\title{
IsTICômetros ${ }^{1}$ : para uma visão e um processo alternativos ${ }^{2}$
}

\section{Isictometrics: toward an alternative vision and process.}

\author{
Professor Michel J. Menou ${ }^{3}$ - E-mail Michel.Menou@wanadoo.fr \\ Department of Information Science, The City University, London, U.K. e \\ Coordenação do projecto Olistica
}

\section{Resumo}

A medição de bens e de fenômenos intangíveis traz dificuldades materiais e conceituais. Como a informação e as tecnologias da informação e da comunicação - TICS se estendem por grande parte da sociedade, a disponibilidade de indicadores válidos é um problema sério. As primeiras tentativas da escola de economia da informação trataram de adaptar as medidas socio-econômicas que existiam à "nova realidade," separando as indústrias e as atividades primárias e secundárias que produzem informação, das relativas aos bens tangíveis. Outros ainda, tentaram medir os fluxos de informação. Muitos reuniram uma mistura de indicadores socio-econômicos de forma a apontar os aspectos chave das transformações que estão acontecendo ou as supostas características de uma "sociedade da informação." Nos últimos anos, a atenção se focou na proliferação das TICS, e, em particular, da Internet, o que resultou em uma variedade de indicadores ou "modelos." Em primeiro lugar, todos estes indicadores se ajustam ao estado e às tendências da evolução da infraestrutura, com uma definição mais ou menos completa desta última incluindo ou não, por exemplo, os recursos humanos e os estoques de informação. Em segundo lugar, muitos estão também considerando o uso da informação, incluindo, possivelmente, as circunstâncias do seu uso. Como o enfoque está centrado nas TICS, chamamos estes esforços de "TICômetros." Poderiam ainda ser chamados de "TachyTICômetros, porque refletem mais a velocidade relativa da difusão das TICS que qualquer outro aspecto. Entretanto, a evolução pela qual passa a sociedade humana é mais complexa e tem um alcance maior do que meramente a disponibilidade e o uso de um certo número de tecnologias. Sustentamos que os indicadores IsTICômetros devem ser selecionados e adaptados considerando a relevância social dos fenômenos estudados. Esta relevância não pode ser relegada aos preconceitos das elites ou dos atores dominantes. É necessário desenvolver um mecanismo participativo com o propósito de vincular as prioridades de desenvolvimento das comunidades à contribuição das TICS para a sua realização, de forma que sejam criados os indicadores correspondentes. $\mathrm{O}$ mesmo mecanismo deveria permitir a aplicação simultânea dos indicadores e seu confronto com realidades e mudanças percebidas, de forma que eles possam ser aperfeiçoados ou eliminados. Uma característica importante deste mecanismo é a apropriação dos indicadores por quem está experimentando as transformações que estão ocorrendo, oposta à imposição comum de indicadores por autoridades intelectuais ou sociais. Chamamos a este esforço de IsTICômetros para o impacto dos TICs na sociedade. Se as TICS revolucionam ou não a sociedade, os atores e especialmente as pessoas que devem desfrutar os seus benefícios, deveriam ter uma participação no processo de formulação de políticas. Por esta razão, elas necessitam dispor de instrumentos e de métodos que lhes permitam julgar o que está ocorrendo. Esta é a intenção do componente metodológico do projeto Olística (http://funredes.org/olistica ).

Palavras-chave: Isictcometria, tecnologias de informação e comunicação

\footnotetext{
${ }^{1}$ Este neologismo foi criado por Michel Menou e Daniel Pimienta e seu uso é aconselhado com base nas regras de "Open text" ou "Copy left".

${ }^{2}$ Uma primeira versão deste documento foi apresentada no Seminário sobre Indicadores de la Sociedad de Información y Cultura Científica, Lisboa, 25-27 junio 2001, organizado por RICYT \& e pelo Observatório das Ciências e das Tecnologias (OCT), Portugal.

${ }^{3}$ Tradução de Miriam Vieira da Cunha
} 


\section{QUEM NECESSITA DE "MEDIDAS" PARA A SOCIEDADE DE INFORMAÇÃO? POR QUE ESTAS MEDIDAS SÃO NECESSÁRIAS?}

Em seu esforço pioneiro para medir a chamada "economia da informação" nos Estados Unidos, Porat \& Rubin (1977) insistiram na necessidade urgente de chegar a uma compreensão justa da natureza desta economia, da forma como funciona e afeta os setores tradicionais, de maneira a diminuir a possibilidade de conseqüências nefastas, como aconteceu na era da revolução industrial. É interessante notar que estes autores não foram ouvidos. Ao contrário, o interesse por novos esquemas de contabilidade nacional que melhor refletiam a economia da informação desapareceu progressivamente. Até certo ponto, a própria economia da informação também desapareceu como centro de interesse até que as "novas" tecnologias de informação e comunicação (TICS) e, singularmente, a Internet trouxeram consigo a "revolução" mais recente.

As TICS são louvadas pelas indústrias que as vendem, pelos governos que querem parecer modernos e pela maioria das pessoas que as utilizam sem realmente reconhecer nelas a força que transforma a sociedade contemporânea. A propaganda é tão forte e disseminada que temos a tentação de perguntar, como faço seguidamente, se o pensamento existia antes do computador, e se era possível existir sem este instrumento. Considerando a fragilidade dos sistemas de computação em rede é legitimo ter sérias dúvidas sobre a possibilidade de sobreviver com ele.

Os anciãos se satisfaziam com os bons presságios dos deuses e com sua suposta benção, testemunhada por realizações exitosas. Como afirmou Paul Valéry, os romanos encontravam idéias mais valiosas nos estômagos de seus frangos sacrificados do que encontramos em nossos cálculos. Não obstante, em uma época dominada pela ciência e pela tecnologia, é importante que as políticas e decisões pareçam fundamentadas no pensamento racional e numa ponderação eficaz de todos os fatores.

A demanda pelo uso de indicadores da sociedade da informação vem, em primeiro lugar, do governo e do setor de informação, em parte, como ingrediente necessário à formulação de políticas, mas também por que isto é facilmente passível de ser explorado em discursos políticos. Tornou-se "moderno" anunciar que "este governo dobrou o número de usuários da Internet" ou ainda que "graças a nossas políticas, esta nação é a primeira do continente no uso da Internet". Outros que apostam neste fenômeno, como as organizações da sociedade civil, deveriam se interessar pelo uso destes indicadores, embora de uma perspectiva diferente, para mostrar, por exemplo, a evolução da brecha digital, ou para pedir apoio. A contribuição atual dos indicadores para a formulação de políticas está longe de ser 
definida se considerarmos as aplicações contraditórias que têm sido feitas (p.ex. um Euro forte estimula a economia européia em relação aos Estados Unidos. Entretanto, a mesma fica mais fraca cada vez que a economia Norte Americana enfrenta problemas). Devemos ainda considerar a falta de significado destes indicadores além da ideologia e da propaganda. Uma informação muito difundida como "todas as escolas estão ou estarão conectadas à Internet" pode referir-se a uma infinita variedade de realidades sem relação direta com a melhoria da educação.

As organizações que têm a responsabilidade pela promoção e operação da aplicação das TICS são, geralmente as interessadas nos dados que se referem ao nível de uso de diversas facilidades, como a qualidade e utilidade do serviço, isto é, a satisfação dos clientes. As conseqüências do uso destes serviços parecem ser uma preocupação mais remota. Isto é natural para as organizações comerciais como os Provedores de Serviços da Internet, cujo volume de negócios ou número de inscritos é, por si, uma indicação de seu resultado positivo. Isto é mais duvidoso para aplicações interorganizacionais: a substituição de centros corporativos de documentos por Intranets não mostra, por si só, um aumento da sua acessibilidade, do seu uso ou da relevância da informação arquivada. A substituição do formato papel pelo eletrônico pode providenciar mais flexibilidade de arquivamento mas, geralmente, repassa para o usuário final as dificuldades e os custos da impressão, fosse so nos casos onde comprovantes estão necessários.

Os provedores de serviços de informação, ou as organizações que os apoiam, têm estado preocupados com o valor de suas atividades para as comunidades ou entidades que servem, provavelmente por causa de sua frustração permanente com sua imagem. Por esta razão, o programa de pesquisa sobre o impacto da informação para o desenvolvimento, promovido pelo Centro Internacional de Investigação para o Desenvolvimento do Canadá (CIID/IDRC) era em parte movido por esta preocupação. (ver, p.ex., o prefácio de M.B. Stone em Menou, 1993). A disseminação mais recente das TICS parece ter trazido um novo credo: as TICS são boas em si mesmas. Quais são os benefícios que trazem? Onde poderiam servir melhor?

Os pesquisadores talvez, sejam mais sinceros em seu desejo de acessar conjuntos pertinentes de dados que possam descrever as características da revolução que estaria acontecendo para que possam entendê-la, ou criar um modelo para tal. Alguns não hesitam em mostrar as TICS como a principal energia vital subjacente a todos os modelos de sociedades contemporâneas, construindo assim castelos de areia. Como a pesquisa científica requer muito tempo e esforço para chegar a resultados incertos, e estes resultados muitas 
vezes não trazem as respostas esperadas pelas forças socio-econômicas dominantes, não é uma surpresa que estas investigações tenham sido bastante limitadas.

Apesar dos seus objetivos distintos, as três perspectivas acima enfrentam o mesmo desafio. Por quanto tempo ainda o princípio militar básico: "Não compreendas o que fazes, mas faça-o rapidamente" poderá produzir resultados positivos? O aprendizado para utilizar as TICS da melhor forma possível é uma preocupação que atinge todos os grupos envolvidos. O Global Knowledge Partnership considerou durante a segunda conferência sobre Global Knowledge Development, (Kuala Lumpur, 2000) um programa transversal conhecido como Learning and Evaluation Action Program (LEAP). Entretanto, a ação para sua realização tem sido lenta e limitada, mas sinais de interesse e de compromisso cada vez mais freqüentes aparecem (ver http://www.bellanet.org/LEAP ).

\section{AS MEDIDAS DISPONÍVEIS E SUAS LIMITAÇÕES}

Em uma revisão da literatura anterior, (Menou, 1985) distinguimos entre as medidas materiais e sociais da informação. Sugerimos ainda que esta última categoria pode se dividir entre estudos setoriais e globais. No primeiro grupo se poderiam identificar tópicos distintos como o tipo de informação, as instituições ou serviços, as técnicas de comunicação ou mensagens e a tecnologia utilizada. No segundo grupo, se podiam identificar, naquele momento, cinco tópicos: a produção e o consumo da informação, os canais de informação, o seu impacto sobre a mudança social, implicações políticas e índices. É necessário acrescentar a este grupo uma sexta categoria, a economia. É fascinante notar que os primeiros índices, tais como o "Informationalisation index", produzido pelo Research Institute of Telecommunications and Economics do Japão, há trinta anos, eram índices compostos com a intenção de abarcar todas as facetas do fenômeno. Em comparação a este índice, as tentativas mais recentes mostram-se bem reducionistas.

As TICS não podem se reduzir à Internet, apesar do lugar importante que ocupa nos diferentes estudos. Os serviços de telecomunicações, a televisão, o rádio, e os sistemas de informática, formam parte deste cenário. As tecnologias tradicionais de comunicação, como o correio, as revistas, os livros, o material impresso, todas as formas de expressão artística e o discurso estão também passando por mudanças. O número de visitas ao Louvre virtual não tem nenhum significado social, a menos que seja comparado com o número de visitas ao museu real, e que se conheça a relação entre estes dois dados e fenômenos. Infelizmente parece que não se leva nunca em conta a comunicação não-digital quando se trata de TICS. Na realidade, um inconveniente maior nos modelos e "medidas" atuais é que não se localizam 
os fenômenos observados em um espaço específico, provavelmente supondo que exista um "ciberespaço" único. Entretanto, enquanto este espaço for ocupado por seres humanos, coexistirá uma esfera de comunicações analógicas (Menou, 2000).

Devemos nos ocupar com um universo relativamente complicado, o que pode ser resumido, no Gráfico 1 abaixo. Para observá-lo e interpretá-lo temos, até agora, 3 tipos de ferramentas: os indicadores econômicos, especialmente dados da contabilidade nacional, os indicadores de desenvolvimento humano e social, alguns indicadores de informação e da infraestrutura das TICS.

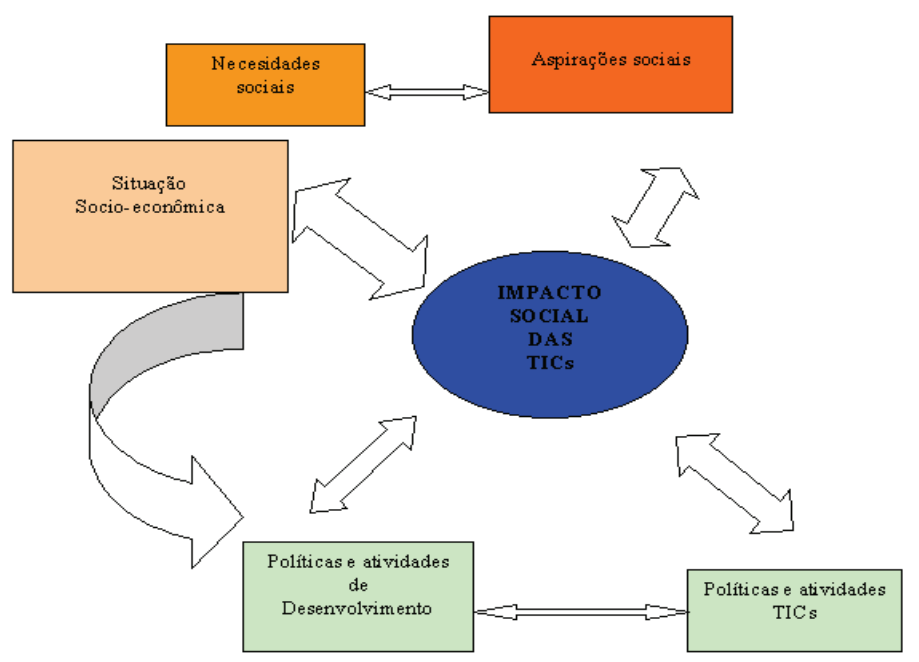

Gráfico 1: O universo que deve ser considerado

Os indicadores econômicos seguem sendo utilizados para mostrar os atributos chave de cada país, embora não sejam apropriados para tal. Poucas tentativas foram feitas para descobrir indicadores compostos que representassem de forma exata o que se chamava, antes da recente queda da NASDAQ, de "nova economia". O "Technology project" do Progressive Policy Institute dos EE.UU e seus indicadores da nova economia são um bom exemplo de tal esforço (http://www.neweconomyindex.org/). Por outro lado, Schware e seus colegas do Banco Mundial (Schware, 1998) combinaram dados sobre o uso da Internet com modelos econômicos com a intenção de apoiar a formulação de políticas. As diferenças entre a imagem fornecida pelos indicadores macroeconômicos e a fornecida pelas medidas específicas da 
informação são significativas, mas não suficientes para invalidar o uso das primeiras (Borko \& Menou, 1982). Também não são tão significativas que possam compensar as dificuldades da construção das últimas e sua credibilidade.

Entretanto, é possível construir um sistema ad hoc de indicadores que possa permitir uma base com mais nuances para a análise do status da informação, como foi feito através do Informalization index (índice de informalização) ou do Index of Information Utilization Potential (índice de Potencial de Utilização da Informação.) O debate sobre a precisão das contas nacionais nas economias de mercado versus economias de planificação centralizada desapareceu com estas últimas. Entretanto, não se pode esquecer que a maioria das medidas econômicas omitem tudo o que não é diretamente relacionado com um rendimento econômico. Não há forma, com as ferramentas existentes atualmente, de contrapor, por exemplo, a potência de saída ou seu equivalente em custo por $\mathrm{kv} / \mathrm{h}$ com o custo da poluição resultante, ou o número de quilômetros percorridos pelos passageiros em deslocamentos para chegar ao trabalho, em relação ao tempo gasto por cada passageiro.

A tecnologia permite, com o tempo, a produção de dados factuais que podem dar uma visão impressionante de alguns assuntos, embora esta visão possa ser, algumas vezes, simplificadora. O gráfico 3 oferece uma visão de conjunto bastante sugestiva da chamada brecha digital, a partir do consumo de eletricidade como se pode observar por satélite. Se a estupidez de algumas políticas pode tomar proporções intergalácticas, infelizmente, não existe nenhum equipamento que possa capturá-las da mesma forma.

Os indicadores sociais são ingredientes fundamentais para o tipo de análise que pensamos elaborar, embora algumas pessoas não acreditem na qualidade de tais indicadores. Uma desvantagem maior destes índices consiste em que as características utilizadas na maioria das análises são pouco relacionadas ao uso das TICS. Um exemplo interessante de sua aplicação potencial pode ser encontrado no projeto Social Impact of the Internet (Impacto Social da Internet) realizado pelo Departamento de Sociologia da Universidade de Maryland (www.webuse.umd.edu/sdaweb/). Este projeto vincula informações de um estudo social a partir de dados sobre o uso da Internet acumulados especialmente para este efeito. Outro estudo promissor pode ser encontrado na adaptação de indicadores de qualidade social para medir a sociedade da informação, proposta por Berman \& Phillips (2001). Estes autores consideram o "input", o processo, os resultados e o impacto da informação relativa à segurança socio-econômica, à inclusão social, à coesão social e à capacitação, a nível de grandes comunidades, como as nações e a nível de comunidades específicas dentro de cada nação. 
As primeiras tentativas que tiveram como objetivo criar indicadores específicos para a informação, ja foram citadas. Elas podem ainda ser aplicadas se seus conteúdos forem revisados de forma a refletir a evolução das TICS. Uma ferramenta desta natureza foi proposta por Mansell \& Wehn (1998) com suas "marcas de pê ". Entretanto, pretender mostrar uma realidade tão complexa como a "sociedade do conhecimento" com apenas 5 parâmetros, parece útil apenas para um apresentador de notícias televisivas. Grande parte da atenção foi dada ao encanto com a propagação da Internet e também à corrida para tornar-se o primeiro país a utilizá-la. O enfoque é, na realidade, a infraestrutura das TICS, embora as preocupações com a sua qualidade também sejam notadas (p.ex. OECD, 1998; Press, 2000). Um quadro mais diversificado foi construído através dos indicadores desenvolvidos pela Leland Initiative da USAID (US NAS 1998a). Estes dados permitiram produzir algumas análises mais aprofundadas, apesar das mesmas estarem fora dos objetivos específicos do programa (Daly, 2000). Embora não se tenha dúvida que o programa influenciou a evolução dos países que o utilizaram, parece um pouco simplista concluir que isso aconteceu somente por causa deste fato.

Uma pesquisa mais recente cujo resultado é interessante é o das séries de avaliações de "E-readiness" (capacitação eletrônica) apoiados pelo programa InfoDev do Banco Mundial. No momento existe apenas um esquema publicado pelo Centro para o Desenvolvimento Internacional na Universidade de Harvard (http://www.readinessguide.org). Sua arquitetura está baseado em 5 pontos: acesso a rede, aprendizagem em rede, sociedade em rede, economia em rede e política em rede. Embora pareça bastante completo, tal instrumento esta principalmente voltado para medir o grau de preparação dos países para a chamada "nova economia". Bridges (2001) realizou uma análise comparativa dos planos e métodos adaptáveis para avaliar a "E-readiness." Os esforços que estão sendo realizados há alguns anos com a meta de desenvolver métodos de avaliação para projetos específicos das TICS, como os telecentros, estão tentando escapar do enfoque simplista sobre a infraestrutura e o uso e chegar até áreas mais remotas onde aparecem impactos. Entretanto, ainda é cedo para prever seu resultado. Dentro dos desenvolvimentos prometedores pode-se aludir ao preparo de um quadro conceitual para avaliar o papel das TICS no desenvolvimento, promovido pelo Centro de Investigação Internacional para o Desenvolvimento do Canadá.

A maioria destes instrumentos tem um enfoque excessivo, embora não exclusivo, na infraestrutura das TICS. Além disso, estes instrumentos são tendenciosos em relação ao desenvolvimento do comércio eletrônico, não como uma medida para melhorar o bem estar dos países em desenvolvimento, mas como uma forma de prover novos mercados para os 
países industrializados. Alguns destes instrumentos tentam enfatizar os efeitos sociais e mesmo as transformações sociais. Entretanto, as necessidades sociais, especialmente como são percebidas pelo povo, estão, na maioria dos casos, ausentes. Se nosso interesse é o crescimento do PIB ou a "Felicidade Nacional Bruta", como afirmamos uma vez (Menou, 1995), há ainda uma grande distância a ser percorrida.

\section{RESTRIÇÕES NA ATUALIZAÇÃO DAS AVALIAÇÕES}

O cenário que encontramos hoje em dia é triste porque não dá para afirmar que, nos últimos trinta anos, muitas mudanças tenham ocorrido. Faltam os ingredientes básicos para um trabalho efetivo, como foi enfatizado em um seminário recente (US NAS, 1998b). Em muitas instâncias, em parte pelas limitações já discutidas, mas também por causa da falta de métodos comprovados e confiáveis e por causa de suas condições particulares, estes estudos são tão específicos que, comparar seus resultados e mesmo acumulá-los, é pouco factível.

Em primeiro lugar, nos falta uma representação geral, ou uma teoria do ciclo da informação e do conhecimento na sua totalidade. A maioria dos conceitos chave é vaga e utilizada de forma inconsistente. É impressionante, por exemplo, que, à primeira vista, não se saiba nunca a que estudos ou notícias da Internet se referem.

Em segundo lugar, em parte como conseqüência do que assinalamos anteriormente, existe escassez de dados, em particular dados estatísticos. Estes dados têm baixa relevância e solidez; pode-se afirmar ainda que sua qualidade é duvidosa, principalmente quando se trata da aplicação das TICS. As tentativas de introduzir atividades e produtos não tangíveis nas classificações standard e nas contas nacionais são, até o momento, falhas. Em muitas instâncias dados brutos foram produzidos através de sondagens, com uma legitimidade questionável, especialmente quando são compiladas por empresas privadas do setor das TICS e absorvidas em estatísticas governamentais . As TICs em si são um complicador. É, por exemplo, quase impossível calcular o número de usuários individuais de contas Internet, pois estes podem variar muito (Menou, 1999). Além disso, uma conta ou ponto de acesso nem sempre significa que esta está sendo utilizada, como pode se verificar com o Minitel ${ }^{4} \mathrm{Em}$ conseqüência as comparações internacionais são especialmente complicadas. Devemos ressaltar ainda que muitas compilações de dados são propriedade comercial privada, ou então não disponíveis livremente. Isto significa que somente as organizações ricas podem obtê-las, o que não é o caso das bibliotecas universitárias mesmo nos países "ricos".

\footnotetext{
${ }^{4}$ Sistema francês de Videotexto (nota da tradutora) 
Um inconveniente mais insidioso é a referência tácita, feita muito freqüentemente, ao modelo de consumo individualista das sociedades "mais avançadas". Não só existe, atualmente, um uso coletivo, mas é bem possível que tal tipo de uso seja o mais apropriado ou o mais razoável em muitos casos (Menou, 2001). É surpreendente ouvir falar da "importância e da urgência" de IPV6 cuja realização permitirá a refrigeradores dos países do Norte se conectarem ao supermercado mais próximo enquanto milhões de pessoas não tem acesso a um telefone público. Outro aspecto da imposição ideológica é a suposição tácita que as TICS são novas pois significam progresso, enquanto qualquer "progresso" possa somente ser julgado se compararmos seus aspectos positivos e negativos. A vinculação entre as necessidades atuais e o que é oferecido pela indústria é cada vez mais tênue. Um exemplo disso são os telefones celulares que permitem a milhares de pessoas que não têm nada para dizer fazê-lo em alta voz em locais públicos. Em geral, o fato que todas as análises sejam realizadas dentro do marco da única ideologia dominante do liberalismo internacional de mercado permite distorções destas análises. Ou segue-se utilizando a Vulgata estabelecida ou estas análises serão rejeitadas pelos principais grupos de atores.

As ferramentas e os procedimentos para as avaliações bem como seus resultados são dirigidos aos especialistas. O público está exposto às interpretações feitas pelos autores-chave da tecno-estrutura ou pelos meios de comunicação (que estão sob o controle direto ou indireto desta). Nos anos oitenta, sem muitas provas evidentes, se pretendia que a criação de novos empregos através das TICs compensaria, em grande parte, o desemprego. Vimos ainda uma grande vaga de desemprego, devida, evidentemente, não apenas à difusão das TICS. A mesma euforia artificial sobre a criação de novos empregos no setor das TICS difundiu-se outra vez, há poucos anos, quando as empresas "pontocom" começaram a florescer. Esta mesma euforia desapareceu rapidamente quando estas empresas se tornaram o caminho mais rápido para as agências de auxílio aos desempregados. A preocupação com o papel das TICS aumentou em muitos setores; entretanto, muitas organizações da sociedade civil ainda acreditam que tenham assuntos mais urgentes com os quais se ocupar do que com aqueles vinculados às TICS. Criar condições para uma participação popular efetiva nas avaliações não é uma tarefa fácil. Ainda mais porque a relativa novidade das TICS e suas constantes mudanças dificultam todos os atores bem como observadores de concentrar-se sobre os efeitos, ou sinais de um provável impacto, em vez do seu uso.

Um último inconveniente, bastante complicado, é resultante de uma busca desesperada no sentido de uma casualidade linear que explique os resultados das interações sociais mais complexas com as reações mais simples, ou simplistas. Por exemplo, "mais capacidade para 
apoiar o comércio eletrônico provoca a expansão de empresas pequenas e médias." O senso comum e alguns indícios científicos estabelecem que a mudança da situação "A" para a situação "B", que são, em si, realidades bastante complexas, requer a interação de um grande número de fatores. Na realidade as questões mais importantes são:

A) que conjunto de condições relacionadas às TICS têm melhor possibilidade de provocar a transformação esperada, e

B) quais são as condições necessárias para que o fator de TICS tenha efeitos?

Outra expressão comum desta idiossincrasia é a tentativa de demonstrar o efeito de uma política ou de um programa em particular, quando obviamente este último é apenas um entre muitos fatores que levam à situação observada.

\section{UMA ORIENTAÇÃO ALTERNATIVA}

Chamamos IsTICometria o conjunto de princípios, normas éticas e regras gerais para a organização, construção e utilização dos esquemas que permitem uma avaliação aberta e participativa das conseqüências sociais da aplicação das TICS. Entretanto este trabalho está em um estágio incipiente, embora fundamentado em experiências de muitos anos. Nesta seção descrevemos os seus princípios e intenções.

Como característica de Olística (Pimienta, 2001), os IsTICômetros são uma ferramenta para facilitar o aprendizado coletivo entre as pessoas que apostam no valor social das TICS, nas políticas a ela relacionadas e na sua submissão às exigências de um desenvolvimento humano sustentável e responsável. Embora a monitorização das transformações que estão acontecendo devam iniciar-se de imediato, necessitar-se-ia mais tempo para que os impactos sociais das TICS possam ser observados e apreciados pelas pessoas que acreditam nisso. Além das realizações, como, por exemplo, o aumento do número de redes comunitárias, parece-nos que o mais importante é a compreensão deste processo e os fatores que dificultam ou que facilitam esta tarefa. $\mathrm{O}$ enfoque convencional no rendimento, nas classificações, na vantagem competitiva, etc, não faz parte de nossos princípios de planejamento. As comparações são consideradas por nós somente como uma facilidade adicional, ou mesmo um requisito, para assinalar as características de uma situação em particular. Também poderão ser utilizadas, em uma etapa posterior, como argumento para influir em debates políticos, mais estamos neste caso fora do domínio da análise.

Um primeiro grupo de proposições de base subjacentes aos IsTICômetros é que os esquemas para análises ou "medidas" e os indicadores da "sociedade da informação" deveriam ser transparentes, modulares, flexíveis e coerentes. Poderiam representar todas as facetas da 
sociedade da informação ou do conhecimento. Deveriam ser compreensíveis e ter um mesmo significado para todos os seus beneficiários. Na prática, isso significa que os critérios e "medidas" ou indicadores devem ser validados pelos representantes dos beneficiários ou atores. Esta tem sido uma característica básica do esquema preliminar das avaliações do impacto de informação, elaboradas pelo programa de investigação internacional do IDRC sobre este assunto. que foi difícil de ser implementado devidos às suas circunstâncias específicas (Menou, 1993 e 2000b). É impressionante constatar que a maioria dos indicadores em uso pelas políticas econômicas e sociais são construções artificiais. Parece-nos que a esperança de vida de 30 anos não é exatamente um dado excitante. Entretanto, não há evidências que a expectativa de vida de 100 anos seja tal para todo mundo, mas isto é um testemunho do "poder da medicina moderna," o que, na realidade é assunto de interesse para um determinado grupo de lobistas. Os esquemas de avaliação deveriam ser flexíveis a adaptações relacionadas a situações ou preocupações específicas, mas deveriam preservar tanto sua coerência como a sua comparabilidade interna através destas adaptações. O projeto Olística impõe uma especial exigência quanto a este ponto, já que as suas observações e interpretações serão realizadas de forma aberta e participatória em uma rede descentralizada.

Outro grupo de premissas de base é que os esquemas utilizados para a análise são apenas representações e interpretações. Eles podem ser úteis para aprofundar assuntos, formular hipóteses, buscar explicações, especialmente as não convencionais. Em outras palavras, são uma ajuda para a reflexão. Alguns esperariam que fossem um incentivo ao "pensamento paralelo". Possivelmente. Mas não são, nem deveriam ser, fórmulas mágicas para tomar decisões. A paixão pelo "mais, mais rápido e melhor que os outros" nos leva a aberrações. Pode-se prever, por exemplo, que $100 \%$ da população tenha uma conta na Internet, o que colocaria cada país ou comunidade numa posição invejável. Mas não é seguro que as crianças o necessitem, nem que muitos adultos o queiram realmente. Este objetivo pode ser alcançado se as organizações como o serviço postal providenciava um endereço Internet para cada pessoa. Mas se não existe uma evolução paralela da rede, na prática os endereços ficarão inutilisáveis. Qualquer semelhança do exemplo acima com uma situação real é puramente fortuita.

A IsTICometria deveria incluir:

1. Uma lista sistemática, embora não limitada de antemão, das necessidades e dos fenômenos sociais que tenham interação com as TICS e suas aplicações;

2. Uma série de ferramentas, critérios, ou indicadores, para avaliar o valor social das TICS;

3. Normas para o uso destas ferramentas: 
4. Normas éticas para a análise das políticas e a divulgação dos resultados;

5. Uma compilação das lições aprendidas na análise de políticas de TICS e em situações específicas;

6. Uma compilação das obras e das revisões originais do citado anteriormente referente à avaliação e medida dos efeitos sociais das TICS.

As premissas acima significam que a construção de uma única ferramenta universal não será possível, por enquanto. Em todo caso, assume-se que se poderia começar com uma série de ferramentas simples, ou IsTICômetros, que serão experimentados conjuntamente com os diferentes temas e locais em que o projeto Olística estará envolvido. Estas ferramentas foram inicialmente definidas tendo como base as discussões que ocorreram durante o projeto Mística (http://www.funredes.org/mistica) e, possivelmente, são uma combinação de:

1. Temas específicos, tais como educação, democracia, economia e produtividade, língua e cultura, saúde;

2. Temas horizontais, tais como gênero, população marginalizada, meio ambiente, influências externas;

3. Países

Quando for apropriado, outras avaliações gerais serão realizadas como parte do projeto Olística, e esquemas de avaliação ou indicadores disponíveis em outros locais comprovados, únicamente com propósito comparativo. Com o tempo poderão ser realizadas adaptações ad hoc com o propósito de ajustar melhor as ferramentas a determinados fenômenos sociais. Por exemplo, o número de websites para cada 1000 habitantes é inapropriado como medida de produção de conteúdo em um país com uma taxa de analfabetismo de $30 \%$, mas seria interessante usando um "ratio" da população alfabetizada por 1000. O conjunto de ferramentas acima descritas será complementado por uma documentação sistemática a partir das lições tiradas de sua produção e aplicação.

A construção dos IsTICômetros será um processo coletivo e interativo durante muito tempo. Um esforço inicial será necessário, abarcando as seguintes etapas:

1. Reunir documentação de base (em execução);

2. Elaborar os critérios que reflitam o valor social das TICS;

3. Analisar os modelos existentes, os esquemas de avaliação e as medidas;

4. Revisar os pontos acima (3) de acordo com critérios de visão social;

5. Produzir documentos básicos da IsTICometria;

6. Desenvolver protótipos de IsTICômetros, conforme requerido nos casos iniciais;

7. Capacitar observadores e participantes no uso dos protótipos; 


\section{Utilizar os protótipos;}

9. Analisar o processo e os resultados;

10. Revisar os documentos básicos da IsTICometria e os protótipos.

Depois deste "empurrão" inicial, espera-se que os vários grupos de observadores possam cumprir as seguintes interações por si mesmos, o que permitiria à coordenação do projeto consolidar as experiências.

Embora existam muitas referências sobre a "visão social" das TICS, sua definição é, até o momento, difusa e vaga sendo o equivalente a "útil ao público em geral." Cada grupo de pessoas que apostam nisso pode apresentar seu caso como estando de acordo com esta visão, principalmente em um momento em que a confusão de gêneros está sendo a regra e a mentira a pedra angular da comunicação institucional. Rever este conceito e tentar articulá-lo de uma forma mais específica e prática será o primeiro objetivo da construção da IsTICometria.

Pode-se começar este trabalho extraindo dos documentos sobre políticas, bem como dos vários estudos e ferramentas de avaliação referentes às TICS ou aos campos a elas vinculados, como informação ou inovação, os temas que assinalem benefícios sociais. Isto resultaria em uma lista de temas gerais que podem se converter em assuntos específicos referentes a áreas de impacto apropriadas. Outra possibilidade é perguntar aos representantes dos vários grupos envolvidos quais são as características de uma sociedade melhor, ou o que faria com que se sintam melhor. Uma matriz, como mostra a Figura 2, abaixo, poderia ser utilizada para compilar informações que poderiam ser coletadas a partir de uma variedade de fontes como documentos, informantes chave, grupos de enfoque ou levantamentos. Deve-se salientar que, excluindo os métodos empregados para acumular dados primários, o conteúdo da matriz deverá ser validado por representantes de todos os grupos envolvidos. No decorrer do processo, a conclusão de cada etapa deverá ser validada da mesma forma. Por outro lado, os critérios utilizados para formular estas conclusões deveriam ser validados pelos representantes de todos os grupos envolvidos.

Figura 2. Matriz de assuntos de impactos que devem ser investigados

\begin{tabular}{|l|l|l|l|l|}
\hline ÁREAS DE IMPACTO & ASSUNTOS & PRIORIDADES & $\begin{array}{l}\text { efeitos Positivos } \\
\text { esperados das TICs }\end{array}$ & $\begin{array}{l}\text { efeitos negativos } \\
\text { possíveis das TICs }\end{array}$ \\
\hline Vida pessoal & & & & \\
\hline Vida familiar & & & & \\
\hline Vida social (em sentido restrito) & & & & \\
\hline
\end{tabular}




\begin{tabular}{|l||l|l|l|l|}
\hline Vida social (em sentido lato) & & & & \\
\hline Cidadania & & & & \\
\hline Vida profissional & & & & \\
\hline Vida econômica & & & & \\
\hline
\end{tabular}

Afirma-se, por exemplo, que as TICS, e, em particular, a Internet, são essenciais para o aprendizado contínuo. Esta noção é uma das mais confusas da era "pós-moderna", pois o aprendizado é uma parte integral da vida. Ela mostra a habilidade dos criadores de marketing e comunicação em converter o senso comum em "non sense." Suponhamos que o aprendizado contínuo seja apontado como uma grande façanha. Pode-se fazer uma lista de cada área de impacto que mostre os assuntos ou fatores mais críticos que impedem o aprendizado contínuo e/ou o inverso, que facilitam este aprendizado. A cada assunto identificado pode ser dado um nível de prioridade relativo. Por exemplo, a oferta de programas adequados é mais importante que seu baixo custo. Pode-se então indicar com precisão os efeitos positivos/negativos que as TICS podem ter em relação a esta limitação. Tendo feito isto para todas as características importantes da sociedade, é possível selecionar as que melhor possibilitem sinalizar o papel crítico das TICS. Então será possível realizar avaliações específicas sobre aspectos particulares e/ou estabelecer mecanismos para monitorá-los com o propósito de verificar se os efeitos positivos ou negativos que eram esperados ocorreram. Nesta fase, a matriz do Gráfico 3 pode se converter na Figura 3, mostrado a seguir.

Figura 3. Matriz de efeitos das TICS observados.

\begin{tabular}{|l||l|l|l|l|l|}
\hline Áreas & $\begin{array}{l}\text { Aspectos dos } \\
\text { assuntos } \\
\text { prioritários }\end{array}$ & Efeitos positivos das TICS & Efeitos negativos das TICS \\
\hline \hline & & Esperados & Observados & Temidos & Observados \\
\hline Vida pessoal & & & & & \\
\hline Vida familiar & & & & & \\
\hline $\begin{array}{l}\text { Vida social (em sentido } \\
\text { restrito) }\end{array}$ & & & & & \\
\hline Vida social (em sentido lato) & & & & & \\
\hline Cidadania & & & & \\
\hline Vida profissional & & & & \\
\hline Vida econômica & & & & \\
\hline
\end{tabular}


Idealmente, cada linha seria traduzida em um par de indicadores que assinalariam as evoluções positivas e negativas. Se, como ocorre freqüentemente, os indicadores podem ser muito abstratos ou distantes dos fenômenos que se deseja ressaltar, pode ser suficiente fazer informes curtos que descrevam os efeitos positivos e negativos e checar se são percebidos como verdadeiros, através de um painel. Uma série de julgamentos deste tipo durante um determinado período de tempo, complementados por fatos que os apoiem, quando isto for possível, poderia resultar numa base bastante sólida.

A equipe de observadores fará, então, a análise das matrizes extraindo as conclusões apropriadas. Estes resultados deverão ser organizados e preparados para uma apresentação aos representantes dos vários grupos de pessoas envolvidas. Uma vez validadas, as conclusões podem ser consideradas como "definitivas." Entretanto, nosso objetivo não é produzir análises por si, mas produzir análises que possam ser efetivamente usadas pelos interessados, mais explicitamente pelas organizações da sociedade civil, de forma a articular suas posições e propostas para as políticas e o desenvolvimento socialmente responsável das TICS. A qualidade destas propostas e o seu êxito servirão como critério para considerar a eficácia da IsTICometria.

\section{A GUISA DE CONCLUSÃO}

A tarefa, tal como se apresenta, é complexa e difícil. Pode ser realizada somente se houver uma cooperação efetiva entre todos os interessados. Olística e seus componentes metodológicos é um projeto cooperativo. Agradecemos a contribuição de todos os que compartilham nossas preocupações. O processo de fortalecimento da sociedade civil nas discussões sobre política das TICS é mais importante que o produto final. Isto é particularmente relevante quando as forças da tecno-estrutura estão impondo uma propaganda sem precedentes para sustentar seus pontos de vista.

O processo de fortalecimento não pode contar somente com a apropriação da IsTICometria. Na realidade, a observação do processo de formulação das políticas em todos os níveis, como do seu resultado, os documentos de política, demostra que todos lutam com conceitos básicos e buscam sinalizações e perspectivas apropriadas.

A quantidade de imitações, atestada pelas fontes e exemplos citados, entre os países do mesmo grupo, e, pior ainda, do "Norte" pelo "Sul" dá medo. A construção de um recurso aberto de material educativo e de ofertas apropriadas de educação neste âmbito são necessidades críticas as quais, infelizmente, não se dá a devida importância. Podemos nos 
perguntar se isso é puramente incidental, Entretanto gostaríamos de fazer uma chamada para a mobilização da pericia e energia disponíveis de forma a ocupar este espaço.

\begin{abstract}
Measurement of intangible goods and phenomena is fraught with material and much more conceptual difficulties. As information and ICT pervades most aspects of society, the availability of meaningful indicators becomes an ever more vexing problem. Early attempts in the information economy school tried to adjust existing socio-economic measures to the "new" reality by separating primary and secondary information industries and activities from those related to tangible goods. Others tried to actually measure information flows. Many assembled a mix of socio-economic indicators deemed to point to key aspects of the transformations taking place or the supposed characteristics of an "information society". In the past few years attention has been focused on the spread of ICT, and of the Internet in particular, giving birth to a variety of indicators or "models". They all are geared in first place to the state and evolutionary trends of the infrastructure, with a more or less comprehensive definition of the latter, e.g. including or not human resources and information stocks. In second place many are also considering information use, possibly including the circumstances of use. Because we see their focus in the ICT themselves, we call these efforts "ICTometrics". They might rather be called "TachICTometrics" so much they are concerned with the relative speed of diffusion of ICT at the expense of other aspects. The evolution human societies are undergoing is however much more complex and far reaching than the simple availability and use of a set of technologies. We contend that ICTometric indicators need to be selected and adapted in consideration of the social relevance of the phenomena they point to. Social relevance itself cannot be left to preconceptions of the elite or dominant actors. A participatory mechanism should be put in place with a view to link development priorities of the communities with the eventual contribution of ICT to their achievement and devise the corresponding indicators. The same mechanism should allow for an ongoing application of the indicators and their confrontation with realities and perceived changes so that they can be fine tuned, or discarded. An important feature here is the appropriation of the indicators by those who are experiencing the transformations under way, as opposed to the common imposition of indicators by intellectual or social authorities. We call this effort "IsICTometrics" for Impact on Society of ICT. Whether or not ICT are revolutionizing societies, actors and especially the people supposed to enjoy its unprecedented benefits should be able to have their say in the process of policy formulation. To that end they need to have instruments and methods that allow them to judge what is occurring. This is the purpose of the methodological component of the Olistica project (http://funredes.org/olistica).
\end{abstract}

Keywords: Isictcometrics, information and communication technologies

\title{
REFERÊNCIAS BIBLIOGRÁFICAS
}

BERMAN, Y.; PHILLIPS, D. Information and social quality. Aslib Proceedings, v.53, n.5, p.179-181, 2001.

BORKO, H. ; MENOU, M.J. Index of information utilization potential: pilot project, section 1, phase 2. Los Angeles, CA: Graduate School of Librarianship and Information Science, University of California Los Angeles, March 1982. 113 p. Draft final report. General distribution. 
BORKO, H. ; MENOU, M.J. Index of information utilization potential: Pilot project, Section 2, Phase 2. Los Angeles, CA: Graduate School of Librarianship and Information Science, University of California Los Angeles, March 1982. 92 p. Draft Final report. General distribution.

BRIDGES Comparison of E-Readiness Assessment Models. Final draft. Washington, DC: Bridges, 2001. v. 2.13.

DALY, J.A. Studying the impacts of the Internet without assuming a technological determinism. In: NICHOLAS, D.; Rowlands,Ian (Eds.). The Internet: its impact and evaluation. INTERNATIONAL FORUM HELD AT CUMBERLAND LODGE, 1999, Windsor Park. Proceedings...London: Aslib, 2000. p.76-100.

MANSELL, R.; WHEN,U.(Ed.). Knowledge societies: Information technology for sustainable development. Oxford, Oxford University Press. 1998.

MENOU, M.J. Assessing methodologies in studies of the impact of information: A synthesis. In: HORTON JR, F.W. (Ed.). Defining and assessing the impact of information on development: building research and action agendas. The Hague: FID, 2000b. p. 65-71.

MENOU, M.J. Digital and social equity? opportunities and threats on the road to empowerment.In: LIDA -Libraries in the Digital Age: ANNUAL COURSE AND CONFERENCE,2001, Dubrovnik. Proceedings... Croatia, 2001. 7p. 23-27 May. Invited paper.

MENOU, M.J. Electronic communications in African development: Tracking their impact. In: MACDONALD, S.; NIGHTINGALE, J. (Eds.). Information and organization: a tribute to the work of Don Lamberton. Amsterdam: Elsevier, 1999. p. 371-392.

MENOU, M.J.. From Data to Wisdom: Is I.T. contributing to Gross National Happiness? In:LAMBERTON, D.M.(Ed.). Beyond competition: The future of telecommunications. Amsterdam:Elsevier, 1995. cap. 6, p. 71-94.

MENOU, M.J. Impact of the Internet: some conceptual and methodological issues, or how to hit a moving target behind the smoke screen. In: NICHOLAS, D. ; Rowlands,Ian (Eds.). The Internet: its impact and evaluation. Proceedings of an international forum held at Cumberland Lodge, Windsor Park,16-18 July 1999. London: Aslib, 2000a. p. 48-64.

MENOU, M.J. (Ed.). Measuring the impact of information on development. Ottawa: IDRC, 1993.

MENOU, M.J. An overview of social measures of information. Journal of the American Society for Information Science, v.36, n.3, p. 169-177, 1985.

OECD. Internet infrastructure indicators. Paris: OECD. 2001. DSTI/ICCP/TISP(98)7/ Final.

PIMIENTA, D. Olistica. La búsqueda de maneras alternativas de concebir indicadores en el contexto de la sociedad de la información. In: SEMINAR ON INDICATORS OF THE INFORMATION SOCIETY AND SCIENTIFIC CULTURE,2001, Lisbon.

PORAT, M.U. ; RUBIN, M.F. The information economy. Washington, D.C: US Department of Commerce, 1977. v. 1.

PRESS, L. Surveying the global diffusion of the Internet. In: INTERNATIONAL FORUM HELD AT CUMBERLAND LODGE, 1999,Windsor Park. Proceedings... London: Aslib, 2000. p. 145-155. 
SCHWARE, R. et al. Economic Internet toolkit for African policy makers. Washington DC: The World Bank, 1998. . Disponível em:

$<$ http://www.worldbank.org/infodev/projects/afprelim.pdf $>$

U.S. National Academy of Sciences Internet counts: measuring the impacts of the Internet. Washington, D.C., NAS Press, 19 98a. Disponível em:

$<$ http://www.bsos.umd.edu/cidcm/wilson/xnasrep2.html $>$

U.S. National Academy of Sciences. Fostering research on the economic and social impacts of information technology: report of a workshop. Washington, D.C., NAS Press. 1998 b. 